Research Paper

\title{
Aberrant FGFR4 signaling worsens nonalcoholic steatohepatitis in FGF21 KO mice
}

\author{
Youxi Yu ${ }^{1,2}$, Xiaoju Shi1,2, Qianqian Zheng ${ }^{3}$, Xingtong Wang4, Xingkai Liu², Min Tan¹, Guoyue Lv², Ping \\ Zhang ${ }^{2 凶}$, Robert C. Martin ${ }^{1}$, Yan Li ${ }^{1 凶}$ \\ 1. Department of Surgery, School of Medicine, University of Louisville, Louisville, KY 40202, USA. \\ 2. Department of Hepatobiliary and Pancreatic Surgery, The First Hospital of Jilin University, Changchun 130021, China. \\ 3. Department of Pathophysiology, Basic Medicine College, China Medical University, Shenyang 110122, China. \\ 4. Department of Tumor Center, The First Hospital of Jilin University, Changchun, Jilin, China.
}

$\triangle$ Corresponding authors: Ping Zhang, MD, PhD, Department of Hepatobiliary and Pancreatic Surgery, The First Hospital of Jilin University, Changchun, Jilin, 130021, China. No. 71. Xinmin Street, Changchun, Jilin 130021, China; Email: azhengpinga@126.com; Telephone: +86-431-88782222; Fax: +86-431-88782222; and Yan Li, MD, PhD, Division of Surgical Oncology, Department of Surgery, University of Louisville School of Medicine, 511 S Floyd ST MDR Bldg Rm324, Louisville, KY 40202; Phone: 502-852-7107; E-mail: Yan.li@louisville.edu

(C) The author(s). This is an open access article distributed under the terms of the Creative Commons Attribution License (https://creativecommons.org/licenses/by/4.0/). See http://ivyspring.com/terms for full terms and conditions.

Received: 2021.01.28; Accepted: 2021.05.24; Published: 2021.06.22

\begin{abstract}
Background: Nonalcoholic steatohepatitis (NASH) is the most severe form of non-alcoholic fatty liver disease (NAFLD) and a potential precursor of hepatocellular carcinoma (HCC). In our previous studies, we found that endocrine fibroblast growth factor 21 (FGF21) played a key role in preventing the development of $\mathrm{NASH}$, however, the FGF15/19 mediated-FGFR4 signaling worsened NASH and even contributed to the NASH-HCC transition. The aim of this study is to determine whether FGF15/FGFR4 signaling could alleviate or aggravate NASH in the FGF21KO mice.

Methods: NASH models were established in FGF21KO mice fed with high fat methionine-choline deficient (HFMCD) diet to investigate FGF15/FGFR4 signaling during early stage NASH and advanced stage NASH. Human hepatocytes, HepG2 and Hep3B cells, were cultured with human enterocytes Caco-2 cells to mimic gut-liver circulation to investigate the potential mechanism of NASH development.

Results: Significant increase of FGF15 production was found in the liver of the NASH-FGF21KO mice, however the increased FGF15 protein was unable to alleviate hepatic lipid accumulation. In contrast, up-regulated FGF15/19/FGFR4 signaling was found in the FGF21KO mice with increased NASH severity, as evident by hepatocyte injury/repair, fibrosis and potential malignant events. In in vitro studies, blockage of FGFR4 by BLU9931 treatment attenuated the lipid accumulation, up-regulated cyclin DI, and epithelialmesenchymal transition (EMT) in the hepatocytes.

Conclusion: The increased FGF15 in NASH-FGF21KO mice could not substitute for FGF21 to compensate its lipid metabolic benefits thereby to prevent NASH development. Up-regulated FGFR4 signaling in NASH-FGF21KO mice coupled to proliferation and EMT events which were widely accepted to be associated with carcinogenic transformation.
\end{abstract}

Key words: Fibroblast growth factor 15/19; Fibroblast growth factor 21; Nonalcoholic steatohepatities; Nonalcoholic fatty liver disease; Bile acid.

\section{Introduction}

Nonalcoholic steatohepatitis (NASH) is the most severe form of non-alcoholic fatty liver disease (NAFLD) and a potential precursor of hepatocellular carcinoma (HCC) [1]. NAFLD advances to the progressive form of NASH in about $44 \%$ of patients [2]. HCC has been recognized increasingly in NASH patients before the cirrhosis stage $[3,4]$. The basis of
NASH-related HCC carcinogenesis remains largely unknown; however, early treatment may determine long-term NASH prognosis [5]. Our previous studies showed that up-regulation of fibroblast growth factor (FGF)15/19 signaling and its receptors FGFR4/betaklotho in NASH-HCC mice and in HCC patients [6, 7]. We also found that lack of FGF21 increased NASH 
severity and ensued pro-inflammatory signaling in the FGF21 knockout (FGF21KO) mice [8]. In a diabetes-HCC mouse model, we found that hepatic FGF21 protein level increased in steatohepatitis but decreased during the development of HCC [9]. Our previous studies indicated that FGF21 played a key role in preventing the development of the major characteristics of NASH: steatosis, inflammation, and metabolic syndrome, however, the FGF15/19 mediated-FGFR4 signaling worsened NASH and even contributed to the NASH-HCC transition.

Fibroblast growth factors are a group of structurally related polypeptides, involved in various biological processes such as neuronal functions, development, differentiation, and metabolism [10]. There are three endocrine FGFs--FGF15/19, FGF21, and FGF23--identified in mouse/human, and human FGF19 is the orthologous gene of mouse FGF15 [11]. FGF21 is predominantly produced by hepatocytes, while FGF15/19 is mostly secreted from the ileum but targeted to liver. Under the regulation of peroxisome proliferator-activated receptor a (PPARa) in response to the accumulation of lipids, hepatic FGF21 elicits metabolic benefits, in turn acting on the distal adipose tissue adipocytes, through the transmembrane receptor FGFR1-coreceptor $\beta$-Klotho complex [12]. This major endocrine action of FGF21 results in a combination of effects including control of lipolysis, clearance of excessive FFAs, enhancing expenditure of the stored lipid energy by mitochondrial substrate oxidation, catabolism and uncoupling, and therefore, negatively regulating hepatic or tissue steatosis, and adiposity [13-15]. As FGF21 acts as endocrine hormones and take part in the regulation of glucose and lipid metabolism [16], pharmacological application of FGF21 holds great promise as effective therapeutic means for treating NASH), obesity and diabetes[17-19]. FGF15/FGF19 has been also reported to prevent NASH [20-22]. Although FGF15/19 upon the mitogenic and cytoprotective effects is critical in protection of hepatocyte from lipid-mediated cellular stress and injury [20], the carcinogenetic role of FGF15/19/FGFR4 signaling has been recognized in various cancers, including breast, gastric, lung, prostate, nasopharyngeal carcinoma and liver cancer [23]. FGF15/19 on glucose metabolism and its crucial regulatory role in bile acid (BA) homeostasis have endorsed FGF15/19's metabolic benefits for whole body lipid metabolism [24]. However, it is not known whether FGF19 signaling in the liver is indispensable against hepatic lipid accumulation to substitute for FGF21 to compensate the metabolic benefits when FGF21 protein is compromised in liver.

In this study, early and advanced NASH models were established in FGF21KO mice fed with high fat methionine-choline deficient (HFMCD) diet to investigate FGF15/FGFR4 signaling during NASH development. We sought to determine whether FGF15/FGFR4 signaling could alleviate or aggravate NASH in FGF21KO mice challenged with HFMCD.

\section{Materials and methods}

\section{Establishing NASH models}

Male FGF21 Knockout (FGF21KO) mice with C57 BL/6J background were generously granted by Dr. Steve Kliewer (University of Texas Southwestern Medical Center). Wild-type (WT) C57 BL/6J mice obtained from Jackson Laboratory (Bar Harbor, ME). Six-weeks old male mice were fed with Rodent Diets, HFMCD (L-amino acid diet with $60 \mathrm{kcal} \%$ fat, $0.1 \%$ methionine and no added choline, A06071302, Research Diets, Inc., New Brunswick, NJ) to induce NASH. Rodent Diet (CD, 10\% kcal\% fat, D12450B, Research Diets, Inc., New Brunswick, NJ) was used as control diet (CD). Both FGF21KO and WT mice with respective diets were assigned randomly into the groups: WT-CD; WT-HFMCD; FGF21KO-CD; FGF21KO-HFMCD. The mice were sacrificed at week 2 for early NASH model and 3 months for advanced NASH model according to previous report [25]. Body weight, liver weight and gross anatomy of liver lobes were determined and evaluated. Serum and hepatic tissues were harvested for further biochemical analysis. Serum alanine aminotransferase (ALT) was measured using an ALT infinity enzymatic assay kit (ThermoFisher Scientific Inc., Waltham, MA). Serum and hepatic triglyceride (TG) was determined using a mouse TG assay kit (Cayman Chemical Company, CA). The animal procedures were approved by the Institutional Animal Care and Use Committee of University of Louisville, which is certified by the American Association for Accreditation of Laboratory Animal Care.

\section{Gross anatomy, histopathological examination and NASH scoring}

The whole liver was isolated, weighted, and examined macroscopically for each animal. The harvested tissues were fixed in 10\% neutral phosphate buffered formalin or embedded in Optimal Cutting Temperature medium (OCT) for liquid nitrogen frozen. The formalin fixed tissues were further embedded in paraffin and sectioned to a thickness of 5 $\mu \mathrm{m}$ for histological and immunohistochemical examinations. Oil Red $\mathrm{O}$ staining for lipid accumulation in the liver tissues was performed in OCT-embedded frozen tissue. Hematoxylin-andeosin (H\&E) staining for histology was performed in paraffin-embedded frozen tissue. The images were 
reviewed and analyzed microscopically for determination of NASH. The Histological Scoring System for NASH is reported by the Pathology Subcommittee of the NASH Clinical Research Network [26]. This scoring system is calculated by the sum of scores of steatosis (0-3), lobular inflammation (0-3) and hepatocyte ballooning (0-2). The scoring is conducted as follows: Steatosis: $0,<5 \% ; 1,5-33 \% ; 2$, $>33 \%$; $3,>66$. Lobular Inflammation: 0 , no foci; $1,<2$ foci/200X; 2, 2-4 foci/200X; 3, >4 foci/200X. Hepatocyte Ballooning: 0, no balloon cells; 1, 1-5 balloon cells/200X; 2, >5 balloon cells/200X.

\section{Immunohistochemical (IHC) analysis}

IHC staining was carried out on the paraffin-embedded tissues using the DAKO EnVisionTM+System Kit (DAKO Corporation, Carpinteria, CA) according to the manufacturer's instructions. Double-IHC staining was performed on the paraffin embedded tissue sections. In brief, endogenous peroxidase was blocked with $3 \%$ hydrogen peroxide, and then with $5 \%$ BSA for $30 \mathrm{~min}$ to block non-specific reaction. These tissue sections were incubated with the first-primary antibodies (see antibody list in supplemental) over night. Tissue sections were incubated with $\mathrm{AP}$-conjugated polymer (1: 300-400 dilutions with PBS) for 1 hour in room temperature, and then incubated with mixture of AP-substrate, AP-activator and AP-chromogen (Abcam, Cambridge, MA) to develop pink color. Tissue sections were then incubated with the second-primary antibodies (see antibody list in supplemental Table 1) for 2 hours in room temperature. Tissue sections were incubated with HRP-conjugated polymer (1: 300-400 dilutions with PBS) for 1 hour in room temperature. Hematoxylin staining was performed before emerald-chromogen staining (Abcam, Cambridge, MA). Tissue sections and then incubated with emerald-chromogen to develop green color. Digital images were acquired with the Olympus $1 \times 51$ microscope (Olympus, Pittsburgh, PA) at $10 x$ magnification using the Olympus DP72 digital camera and the length of scratch-wound was measured via the cellSens Dimention imaging system. Computer image analysis was performed, and the acquired color images from the immunohistochemical staining were defined a standard threshold according to the software specification. The computer program then quantified the threshold area represented by color images.

\section{Terminal deoxynucleotidyl transferase- mediated dUTP nick end labeling (TUNEL) assay}

A TUNEL assay was performed using an
Apop-Tag Peroxidase In Situ Apoptosis Detection Kit (Chemicon, Billerica, CA). Briefly, the deparaffinized and rehydrated tissue sections were treated with proteinase $\mathrm{K}(20 \mathrm{mg} / \mathrm{L})$ for $15 \mathrm{~min}$, and then incubated with terminal deoxynucleotidyl transferase (TdT) and digoxigenin-11-dUTP for $1 \mathrm{hr}$ at $37^{\circ} \mathrm{C}$. Anti-digoxigenin antibody conjugated with horseradish peroxidase (HRP) along with the substrate $\left(\mathrm{DAB}-\mathrm{H}_{2} \mathrm{O}_{2}\right)$ was used for visualization. Apoptosis was quantitatively analyzed by counting the TUNEL positive cells in ten fields for each section at 20X magnification. The apoptotic index was presented as TUNEL positive cells per 100 cells.

\section{Western blot assay}

The protein levels for the biomarkers were semi-quantified by Western blot analysis as described previously [25]. Electrophoresis was performed on $12 \%$ SDS-PAGE gel and the separated proteins were transferred to nitrocellulose membrane. The membranes were incubated with the primary antibodies (see supplemental Table 1 antibody list) overnight at $4^{\circ} \mathrm{C}$ and with secondary antibody for 1 hour at room temperature. The antigen-antibody complexes were then visualized using ECL kit (Amersham, Piscataway, NJ). The protein bands were quantified by densitometry analysis.

\section{Real-Time RT-PCR (qPCR)}

Total RNA was extracted using the TRIzol reagent (Invitrogen). First-strand complimentary DNA (cDNA) was synthesized from total RNA, according to manufacturer's protocol from the RNA PCR kit (Promega, Madison, WI, USA). Quantitative PCR was carried out using the ABI 7300 real-time PCR system (Applied Biosystems, Carlsbad, CA). The primers are listed in supplemental Table 2 . The target mRNA expression was quantified and $\beta$-actin was used as an endogenous reference. Results were expressed as fold change in gene expression.

\section{Cell lines and in vitro study}

The cells for in vitro study include a mouse hepatic cell line, FL83B (ATCC ${ }^{\circledR}$ CRL-2390), human HCC cell lines, HepG2 (ATCC ${ }^{\circledR}$ HB-8065) and Hep3B (ATCC ${ }^{\circledR}$ HB-8064), and a human colorectal adenocarcinoma cell line, Caco-2 (ATCC ${ }^{\circledR}$ HTB-37). The cells were cultured, FL83B cells in the F12K medium (ATCC), HepG2 and Hep3B cells in DMEM medium, and Caco-2 cells in EMEM medium respectively, with $10-15 \%$ fetal bovine serum. To study the effects of FFA on the cell lines regarding the FGF15/FGFR4 signaling, palmitate (PA) media (Sigma, P9767), recombinant mouse (rm) FGF-15 protein (Abcam, ab125734), recombinant human (rh) FGF21 protein (Abcam, ab217404) and BLU9931 
(MedChemExpress, HY-12823), and rhFGF19 (R\&D, 969-FG) were used to treat the cells. PA media was made by dissolving $2 \%$ bovine serum albumin (BSA, US Biologicals, A1311) in cell culture medium and the 100uM PA working solution was prepared from a high concentration $(20 \mathrm{mM})$ stock PA solution made by $\mathrm{dH} 2 \mathrm{O}$ heated to $70^{\circ} \mathrm{C}$. Based on the previous reports, rmFGF15 protein was applied at $100 \mathrm{ng} / \mathrm{ml}$ [27], rhFGF21 protein was applied at $1.1 \mu \mathrm{g} / \mathrm{ml}$ [28], BLU9931 was applied at the concentration of $100 \mathrm{nM}$ [29], for up to 24 hours. rhFGF19 was applied at the concentration of $100 \mathrm{ng} / \mathrm{ml}$ [27], for up to 24 hours. Caco-2 cells were co-cultured with HepG2 or Hep3B cells for up to 24 hours to study the FGFR4 signaling based cross-talk between enterocyte and hepatocytes. Immunofluorescent staining was performed in the cells using FITC-conjugated or PE-conjugated IgG (see supplemental Table 1 antibodies list) and DAPI for counterstaining.

\section{Statistical analysis}

Collected data from repeated experiments were presented as mean \pm SD. Statistical analysis was performed by using SPSS V.17.0. Statistical significance was determined by ANOVA. The post hoc Tukey's test was used for analysis of any differences between groups. Group difference was considered significant for $\mathrm{p}<0.05\left(^{*}\right), \mathrm{p}<0.01\left(^{* *}\right)$.

\section{Result}

\section{Lack of FGF21 worsens the HFMCD-induced NASH in mice}

Based on the previous reports [25], we established an early NSAH model in FGF21KO mice with 2-weeks HFMCD feeding. The gross appearance of NASH liver, unlike the normal liver lobes with red-velvet color, showed diffusely pale-yellow-tan color lobes (Figure S1A) along with increases of liver weight, body weights, glucose tolerance, and serum ALT level in FGF21KO-HFMCD mice (Figure S1B). Increased FGF21 expression by IHC was found in HFMCD feeding WT mice but undetected in FGF21KO mice (Figure S1C). Steatohepatitis was defined in mice, as evident by the histology and confirmed by NAFLD Active Score (NAS) system which was accepted as a surrogate for the histologic diagnosis of NASH. As previously reported in patients with NAFLD, the score of $\geq 5$ strongly correlated with a diagnosis of "definite NASH" whereas the score $\leq 3$ correlated with a diagnosis of "not NASH [26]. All the mice with 2-weeks HFMCD feeding were found with NAS of $>5$ and diagnosed as steatohepatitis. The highest NAS was found in the group of FGF21KO-HFMCD mice, with statistical significance compared to all other groups (Figure 1A). Consistent to NAS, highest protein level of FGF15 by IHC was found in the group of FGF21KO-HFMCD mice, with statistical significance compared to all other groups (Figure 1B). Western blot analysis confirmed the IHC results (Figure 1C). The results indicated that FGF15 protein was significantly increased the liver tissues of FGF21KO mice, however the increased FGF15 protein did not show protection against the HFMCD induced steatohepatitis in FGF21KO mice.

\section{Ileum FGF 15 upregulates hepatic FGFR4- $\beta$-klotho in FGF21 KO-HFMCD mice}

FGF15/19 is an enterokine and expresses abundantly in the distal small intestine. Upon bile acids stimulation, FGF15/19 reaches liver via the portal blood and binds to FGFR4 and co-receptor $\beta$-klotho, triggering a signaling cascade involving hepatic bile acid, lipid and glucose metabolism [30, 31]. FGF15/19 is not physiologically expressed in the liver [32], but pathological FGF19 expression in liver tissues was detected in patients with hepatitis C virus-related cirrhosis or biliary cirrhosis [33]. We further investigated the resource of FGF15 production and hepatic FGFR4/ $\beta$-klotho expressions. The results indicated that significantly increased mRNA expression in the intestinal tissues and increased serum FGF15 protein levels were found in FGF21KO-HFMCD mice, compared to all other groups (Figure 2A-B). However, the mRNA of FGF15 was not detectable in hepatic tissues of all groups of mice (data not shown). A dual IHC staining for FGFR4 and $\beta$-klotho was performed in the liver tissues. The results indicated that FGFR4 and $\beta$-klotho were co-expressed in the hepatocytes, while FGFR4/ $\beta$-klotho expressions were significantly up-regulated in the FGF21KO-HFMCD mice, compared to all other groups (Figure 2C). qPCR and Western blot analysis of liver tissues further confirmed the IHC results (Figure 2D). The results indicated that the hepatic FGFR4/ $\beta$-klotho signaling was significantly upregulated in the FGF21KO-HFMCD mice, implying that severity of NASH might associate to the aberrant FGFR4/ $\beta$-klotho signaling.

\section{FGF 15 is unable to alleviate steatosis but up-regulates FGFR4 in the FGF21KD hepatocytes}

The binding of FGF15/19 to FGFR4/ $\beta$-Klotho not only suppresses BA synthesis in hepatocytes via inhibition of cholesterol 7a-hydroxylase 1 (CYP7A1), the rate-limiting step for bile acid synthesis[34], but also activates signaling cascades leading to increased insulin sensitivity, improved glucose metabolism, and 
body weight reduction while on a high-fat diet[35]. However, it is unknown whether FGF15 can directly alleviate steatosis in hepatocytes. Therefore, we further investigated the effect of FGF15 on steatosis using FL83B cells, a benign mouse cell line of hepatocyte. To mimic the FGF21KO mice, a shRNA assay was performed to knockdown (KD) FGF21 gene in the FL83B cells. Both FGF21KD (21KD) FL83B cells and the shRNA control (shCT) FL83B cells were challenged with palmitic acid (PA) and treated with rmFGF15 or rhFGF21. Lipid accumulation in hepatocytes were detected by Oil-red O staining. The result indicated that PA challenging significantly up-regulated lipid accumulation in both FGF21KD FL83B cells and shCT-FL83B cells, while treatment with rhFGF21 attenuated the up-regulated lipid accumulation. Unlike FGF21, FGF15 treatment did not show the attenuation of up-regulated lipid accumulation in the shRNA control FL83B cells. In contrast, highest level of lipid accumulation was found in the FGF21KD-FL83B cells with FGF15 treatment (Figure 3A). As a regulatory function of hepatic FGFR4 to promote hepatic TG accumulation has been reported previously [36], we further investigated the FGFR4 levels in hepatocytes. FGF15 treatment significantly up-regulated FGFR4 expression in both shCT-FL83B and FGF21KD-FL83B cells challenged with PA, however, FGF21 treatment did not show up-regulation of FGFR4 levels (Figure 3B). We further investigated the major enzymes for de novo synthesis, Fatty acid (FA) esterification and FA transport. Up-regulated FASN, Acc1 and Acc2 (de novo synthesis), Dgat1 and Acat1 (esterification), and Mttp, Apoo1 and CD36 (transport) were found in FGF21KD-FL83B cells challenged with PA (Figure 3C), implying that the increased TG storage in hepatocytes could be either from de novo synthesis or FFAs uptake. Taken together, the bioactivities of FGF15 on hepatocytes, instead of alleviating lipid accumulation, was shown to up-regulate FGFR4, while compromised FGF21 worsened steatosis in hepatocytes.

\section{NASH progression is associated with the up-regulated FGFR4 levels in FGF21 KO mice}

Although the FGFR4 mediated-benign hepatic TG storage might provide protection on hepatocytes, continuously up-regulated FGFR4 signaling could play a deleterious role contributing to cell proliferation and progression of cancers [23]. According to this hypothesis, we further determined the levels of FGF15 as well its receptors FGFR4/ $\beta$-klotho (KLB) in an advanced NSAH model of FGF21KO mice with HFMCD feeding for 3 months. Unlike the early stage NASH model, the gross appearance of in advanced NASH liver showed diffusely pale-yellow color lobes and increased liver weight along with increased glucose tolerance, liver weight, body weight, and serum TG level in FGF21KO-HFMCD mice (Figure S2). Of note, when we analyzed the morphological changes of NASH liver, multiple nodules were detected microscopically in hepatic parenchyma of the liver tissues from FGF21KO+HFMCD mice (Figure 4A). Histological changes showed severe steatohepatitis, as evident by significantly increased NAS, multiple nodules in hepatic parenchyma, significantly increased for Kupffer cells/macrophages detected by IHC for F4/80, and significantly increased serum ALT level in the FGF21KO-HFMCD mice compared to all other groups (Figure 4A). As expected, significantly increased protein levels of FGF15 and FGFR4/ $\beta$-klotho and were detected by Western blot analysis in the liver of FGF21KO-HFMCD mice compared to all other groups (Figure 4B). Overexpressions of FGFR4 and $\beta$-klotho in the liver of FGF21KO-HFMCD mice with advanced NASH were confirmed by IHC and qPCR (Figure S3). Taken together, continuously up-regulated FGFR4 expression in advanced NASH should call attention because hyperactivation of FGFR4 by FGF19 was reported in colon cancer and HCC [37]. However, FGF15/19 was also reported to down-regulate FGFR4 and $\beta$-klotho [27]. Therefore, we further studied the FGFR4 signaling in advanced NASH model in regard of the malignant potential.

\section{Up-regulated FGFR4 signaling is coupled to fibrotic and malignant events in FGF2 $1 \mathrm{KO}$ mice}

Cirrhosis and HCC have become the major liver-related clinical endpoints in NASH, while fibrosis progression and malignant transformation are driven by repetitive damages/repairs via apoptosis and cell proliferation [2]. To study fibrosis and the cellular events, we performed Sirius Red staining for fibrosis, IHC of PCNA for proliferation, and TUNEL assay for apoptosis in the liver tissues from the advanced NASH model with HFMCD feeding for 3 months. Significantly increased level of collagen fiber, as showing the red color by Sirius Red staining, was found in FGF21KO-HFMCD mice compared to all other groups (Figure 5A). Consistent to Sirius Red staining, significantly increased levels of apoptosis and cell proliferation, indicated by the indexes of positive apoptotic cells and positive PCNA cells, were also found in FGF21KO-HFMCD mice compared to all other groups (Figure 5A). To evaluate the potential malignant phenotype, the epithelial-mesenchymal transition (EMT) event was investigated by a dual IHC staining for E-cadherin and vimentin in the liver 
tissues. The results indicated that E-cadherin expression was significantly down-regulated but vimentin expression was significantly up-regulated in the FGF21KO-HFMCD mice, compared to all other groups (Figure 5A). Western blot analysis was further performed in the liver tissues and the results indicated that significant increases of cyclin D1 and cleaved caspase-3 but significant decrease of BCL-2
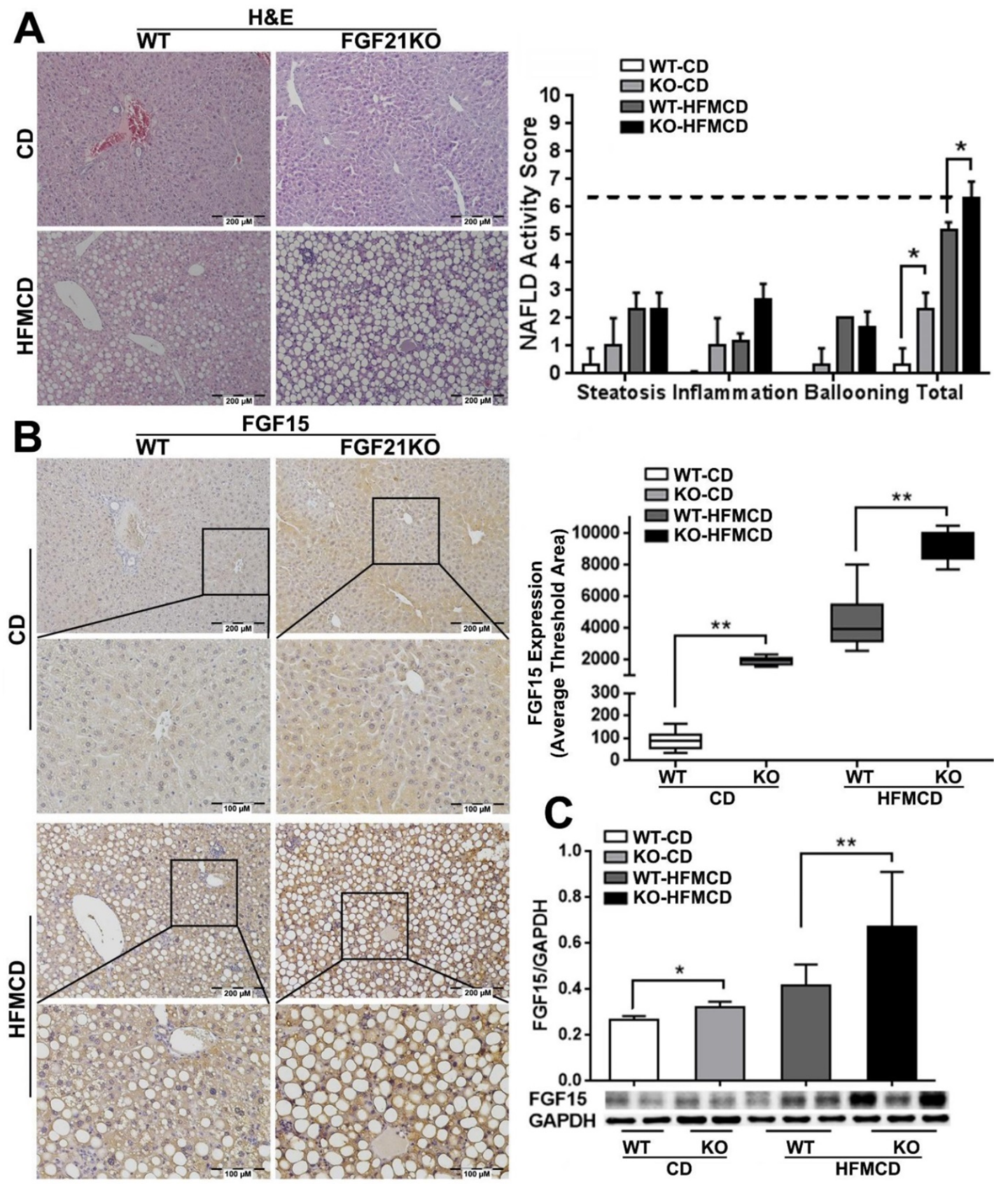

Figure 1. A: Representative histology by H\&E staining and NAFLD activity score (NAS) in the liver tissues from early NASH model and controls. For histological details, bland steatosis was characterized as wildly distributed lipid drops being detected while steatohepatitis was characterized as infiltration of inflammatory cells in the acinar zone and in the form of hepatocyte ballooning being detected. B: Representative images of FGF15 expression by IHC staining along with computer-imaging analysis. C: FGF15 expression by Western blot analysis in the liver tissues from early NASH model and controls. WT: wild type; KO: FGF21KO; CD: control diet; and HFMCD: high fat methionine-choline deficient. *, $\mathrm{p}<0.05 ; * *, \mathrm{p}<0.01$.

was found in FGF21KO-HFMCD mice, compared to all other groups (Figure 5B). Taken together, increased fibrosis and deleterious molecular and cellular events were found in in FGF21KO-HFMCD mice which with advanced NASH, while up-regulated FGFR4 expression was coupled to these molecular and cellular events.

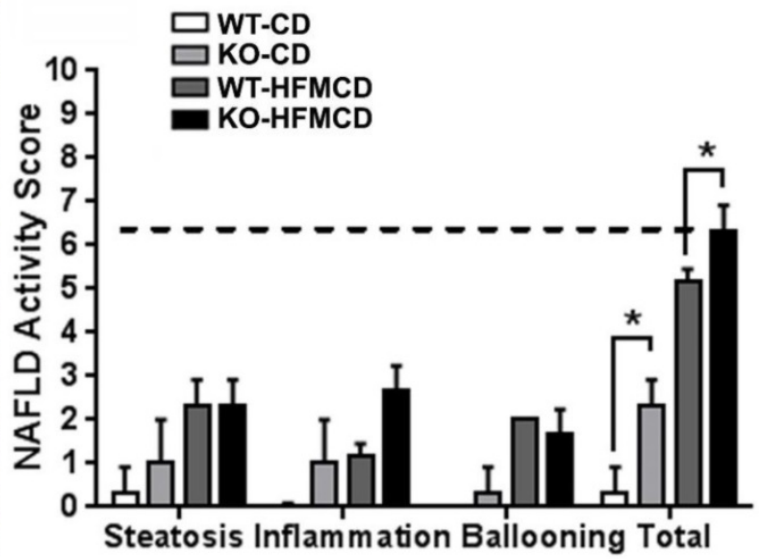



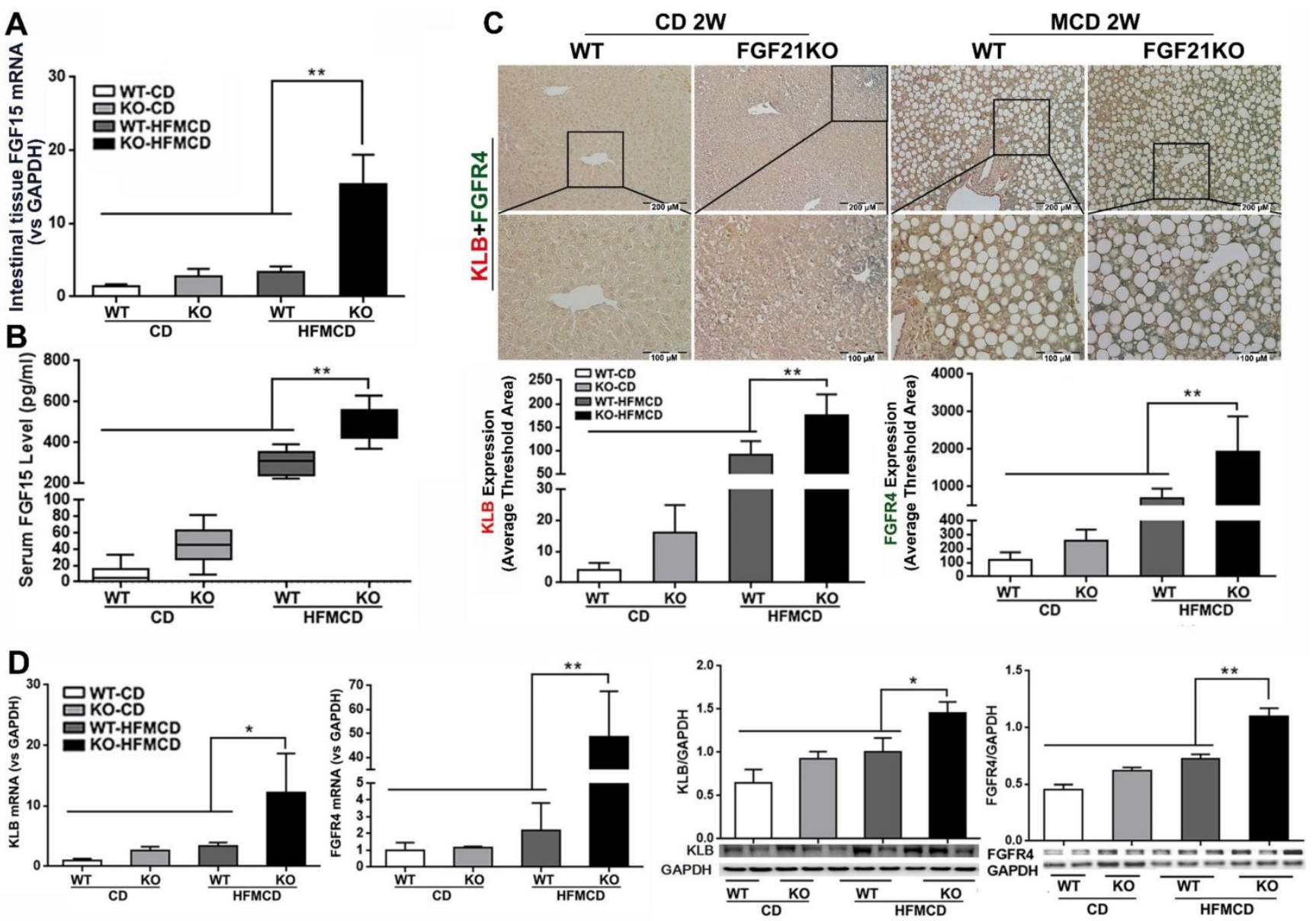

Figure 2. A-B: FGF15 mRNA expression by qPCR in the ileum tissues and FGF15 protein levels by ELISA assay in serum from early NASH model and controls. C: Representative images of FGFR4/ $\beta$-klotho expression by a dual IHC staining along with computer-imaging analysis in liver tissues from early NASH model and controls. D: FGFR4/ $\beta$-klotho mRNA expression by qPCR and FGFR4/ $\beta$-klotho protein levels by Western blot in the liver tissues from early NASH model and controls. KLB: $\beta$-klotho; WT: wild type; KO: FGF21KO; CD: control diet; and HFMCD: high fat methionine-choline deficient. *, $\mathrm{p}<0.05 ;$ **, $\mathrm{p}<0.01$.

\section{Blockage of FGFR4 attenuates proliferation and EMT in hepatocytes and HCC cells.}

To mimic the enterohepatic circulation in regards of the FGF19/FGFR4 signaling, we further performed a co-cultured study using human hepatocyte cell lines (HepG2 and Hep3B) and an enterocyte cell line (Caco-2). When Caco-2 cells co-cultured with either HepG2 or Hep3B, significantly up-regulated FGF19 mRNA was detected in the Caco-2 cells (Figure S4). BLU9931, a highly selective, covalent, small-molecule inhibitor that specifically targets FGFR4, binds within the ATP-binding pocket of FGFR4, forming a covalent bond with Cys552 to specific targeting to FGFR4 [29]. By suing BLU9931, we further performed the studies to investigate whether inhibiting FGFR4 could abolish the FGF19/FGFR4 signaling thereby alleviate the molecular and cellular events related to the NASH pathogenesis. Consistent with the results of co-culture supernatant treatment and rhFGF19 treatment, co-culture with Caco-2 cells significantly increased levels of cyclin D1, while BLU9931 treatment attenuated the up-regulated cyclin D1 levels in both HepG2 cells and Hep3B cells (Figure 6A). The result of Oil Red O staining indicated significantly increased levels of lipid accumulation in Hep3B cells either co-cultured with Caco-2 cells or PA treatment, while BLU9931 treatment attenuated the increased levels of lipid accumulation with statistical significance (Figure 6B). With BLU9931 treatment, significantly decreased protein level of cyclin D1 was also found in FGF21KD FL83B cells either with PA challenging or without (Figure 6C). As EMT has been widely accepted as a cellular event to be associated with tumor initiation, we further used BLU9931 to study whether blocking FGFR4 could inhibit EMT event in FGF21KD FL83B cells either with PA challenging or without. Consistently, blockage of FGFR4 signaling alleviated significantly the EMT in FGF21KD FL83B cells either with PA challenging or without (Figure 7). These results demonstrated that blockage of FGFR4 could attenuate the deleterious cellular and molecular events which might be associated with NASH development and NASH-HCC progression. 


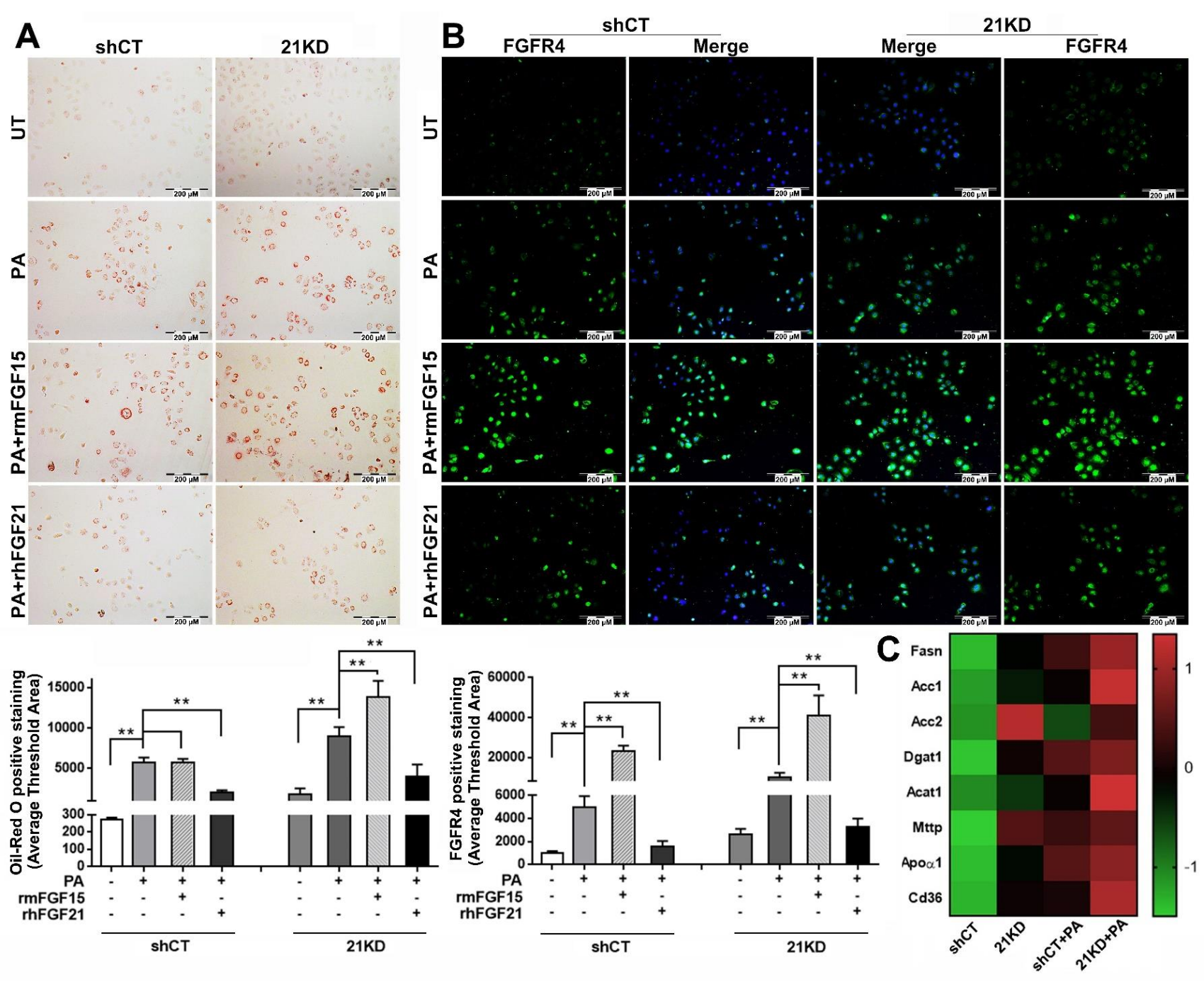

Figure 3. A: Lipid accumulation detected by Oil Red O staining along with computer-imaging analysis in shCT-FL83B cells and FGF21KD-FL83B cells challenged with PA (palmic acid) at $100 \mathrm{uM}$ for 48 hours, and treated with rmFGF15 at $100 \mathrm{ng} / \mathrm{ml}$ and rhFGF21 at $1.1 \mu \mathrm{g} / \mathrm{ml}$. B: FGFR4 expression detected by immunofluorescent staining in shCT-FL83B cells and FGF21 KD-FL83B cells challenged with PA at 100uM for 24 hours, and treated with rmFGF15 at 100ng/ml and rhFGF21 at $1.1 \mu \mathrm{g} / \mathrm{ml}$. C: Alterations of lipid metabolic enzymes in shCT-FL83B cells and FGF21KD-FL83B cells challenged with PA at 100uM for 24 hours. FASN: Fatty Acid Synthase; Accl: acetyl-coenzyme A carboxylase 1; Acc2: acetyl-coenzyme A carboxylase 2; Dgat 1: Diacylglycerol acyltransferases 1; Acatl: Acyl-CoA:cholesterol acyltransferase 1; Mttp: Microsomal triglyceride transfer protein; Apoa 1: apolipoprotein $\alpha-1$. UT: untreated; PA: palmic acid; shCT: shCT-FL83B cells; 21KD: FGF21KD-FL83B cells. **, P<0.01.

\section{Discussion}

As a liver safeguard [38], FGF21 was widely reported to alleviate hepatic fat stress via directly reducing hepatic lipid accumulation in an insulin-independent manner [39]. Similar to FGF21, FGF15/19 was also reported to function in controlling whole body lipid metabolism through increasing energy expenditure, FA oxidation, and decreasing de-novo lipogenesis [20]. However, it was unknown whether FGF15/19 could directly reduce hepatic lipid accumulation, especially when FGF21 was not function well, i.e., FGF21 resistance in obesity [40]. In this study, significant increase of FGF15 production was found in the NASH-FGF21KO mice. As previously reported [10], both of FGF15/19 and FGF21 involved in the biological process of lipid metabolism but the modulating pattern showed different. FGF21 can be rapidly produced in hepatocytes by fasting in mice while FGF15/19 is secreted from enterocytes upon bile acids stimulation. The possible reasons for overexpression of FGF15 in NASH-FGF21KO mice could be that: 1) the high fat diet caused over-secreted bile acids; 2 ) the severity of $\mathrm{NASH}$ in FGF21KO mice caused overexpression of FGF15 to compensate the FGF21. Although overexpression of FGF15 was found NASH-FGF21KO mice, the in vitro study showed that rmFGF15 treatment was unable to alleviate the lipid accumulation in FGF21KO-FL83B cells as evidenced by Oil Red $\mathrm{O}$ staining. In contrast, the up-regulated expressions of FGF15 and FGFR4 were coupled to fibrosis, hepatocyte injury/repair, and potential malignant events in the FGF21KO mice with advanced NASH. 

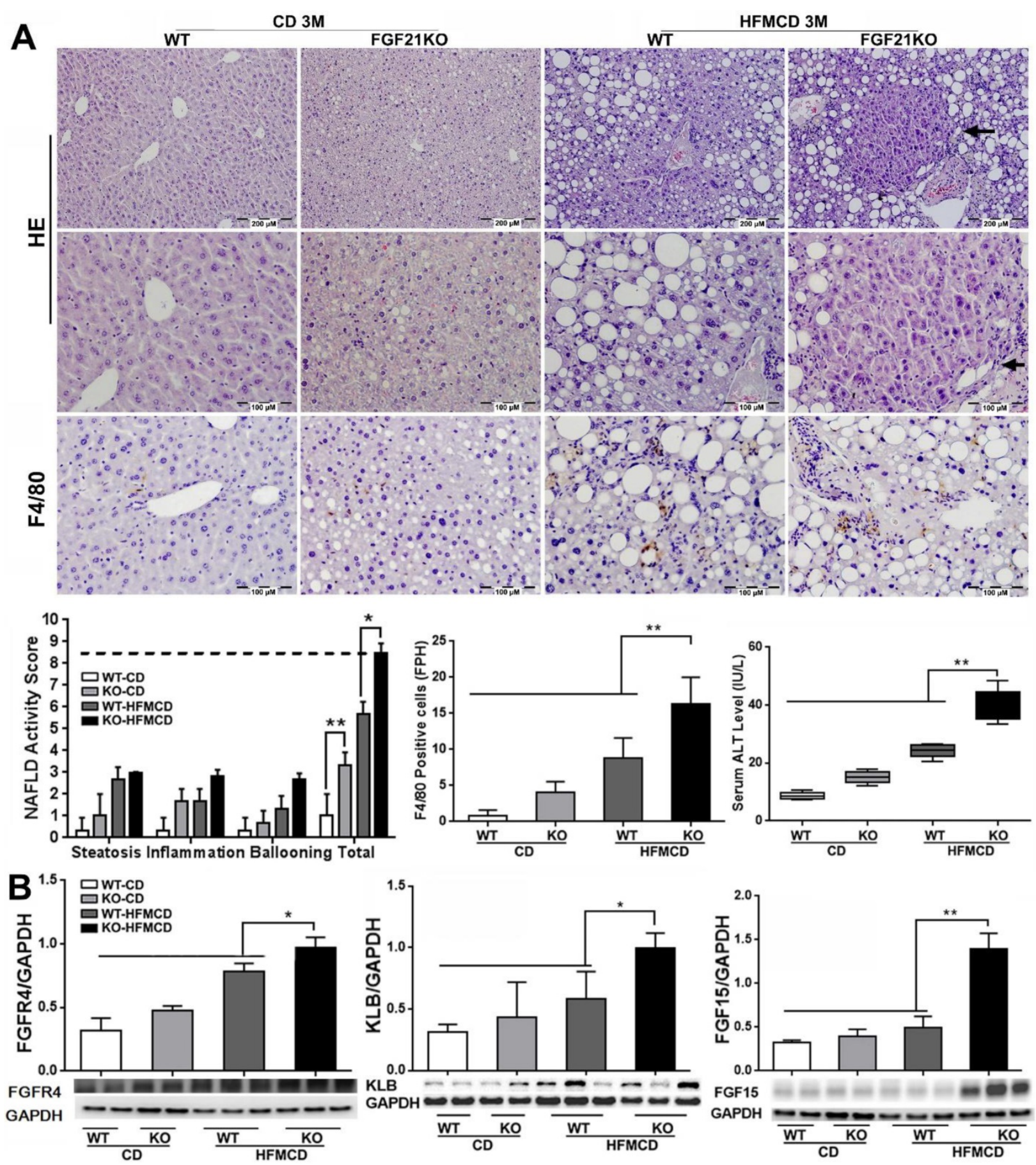

Figure 4. A: Representative histology by H\&E staining and Kupffer cells/macrophages detected by F4/80 staining in the liver tissues from advanced NASH model and controls. NAFLD activity score (NAS) and index of F4/80 positive cells were calculated based on H\&E and F4/80 staining. Arrow: a nodule was detected in the section by H\&E stain in hepatic parenchyma from FGF21 KO+HFMCD mice. B: The protein levels of FGFR4, $\beta$-klotho and FGF15 by Western blot in the liver tissues from advanced NASH model and controls. KLB: $\beta$-klotho; WT: wild type; KO: FGF21KO; CD: control diet; and HFMCD: high fat methionine-choline deficient. FPH: field per high power. *, $\mathrm{P}<0.05 ;$ **, $\mathrm{P}<0.01$.

Both FGF15 and FGF19 function as a negative feedback loop shutting down BA synthesis when BAs levels are high in the intestinal mucosa. Regarding the bioactivity on NASH, studies either from transgenic mice or treatment with FGF19 protein have shown that FGF19 alleviates lipid accumulation in the liver and thereby prevents NASH $[20,41,42]$. However, the effect of FGF15 on NASH is reportedly contradictory. For example, a study reported that the FGF15 knockout mice fed a HFD worsened steatosis [20] but another study that also fed with HFD to the FGF15 knockout mice did not show worsened steatosis severity[43]. The protein discrepancy between FGF15 and FGF19 has been identified previously, in which they share only $50 \%$ sequence homology $[30,44]$ even though they are orthologs and both are considered as endocrine FGFs because they do not bind heparin sulfate and thus can escape extracellular matrix. 
Studies using chimeric immunodepressed mice transplanted with human hepatocytes further emphasized the bioactive discrepancy between FGF15 and FGF19, in which FGF19 administration reversed the enlarged bile acid pool size [45], but significantly elevated FGF15 was unable to suppress hepatic CYP7A1 expression [33]. The increased hepatic BAs level not only induces liver injury [46] but also plays an important role in the regulation of hepatocytes regeneration [47], contributing to NASH development through repetitive injury/repair. BAs reabsorbed in the intestine can increase the FGFR4/ $\beta$-klotho levels in hepatocytes for subsequent FGF15/FGFR4 signaling in liver [48], while hepatic FGFR4 is reported to promote hepatic lipid accumulation by either HFD or healthy diet [24,36]. In our study, the significant increased FGF15 in the NASH-FGF21KO mice was unable to alleviate hepatic lipid accumulation, while up-regulated FGFR4 expression was coupled to fibrosis and deleterious molecular and cellular events in advanced NASH. This might be explained by, 1) although FGF15 protein was very high in liver, it was unable to suppress hepatic CYP7A1 expression [33] for BA synthesis and BAs could induce liver injury and cell death [46]; 2) the BAs mediated up-regulation of FGFR4 in hepatocytes [48] could not only promote hepatic lipid accumulation [24, 36] but also induce regeneration [47], causing repetitive injury/repair in liver; and 3) lack of FGF21 further worsened steatosis and the $\mathrm{NASH}$ progression. Our findings indicate a dramatically different roles of FGF15 and FGFR4- $\beta$ klotho during NASH development in FGF21KO mice.
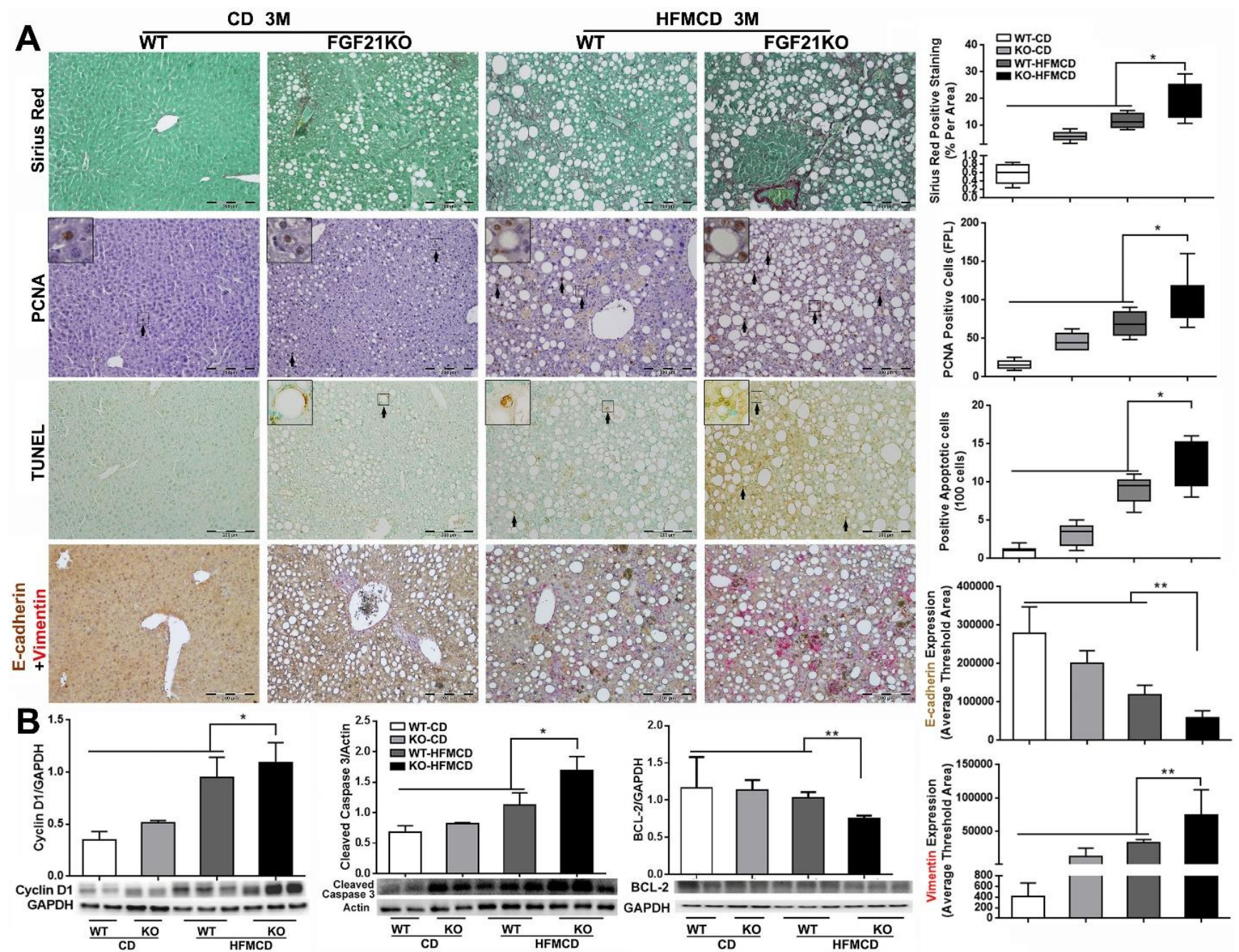

Figure 5. A: Representative images of Sirius Red staining, PCNA and TUNEL by IHC staining, E-cadherin/Vimentin by a dual IHC staining along with computer-imaging analysis in liver tissues from advanced NASH model and controls. B: Western blot analysis for the protein levels of cyclin D1, cleaved caspase-3 and BCL-2 in liver tissues from advanced NASH model and controls. WT: wild type; KO: FGF21KO; CD: control diet; and HFMCD: high fat methionine-choline deficient. FPL: field per low power. *, p<0.05; **, p<0.01. 

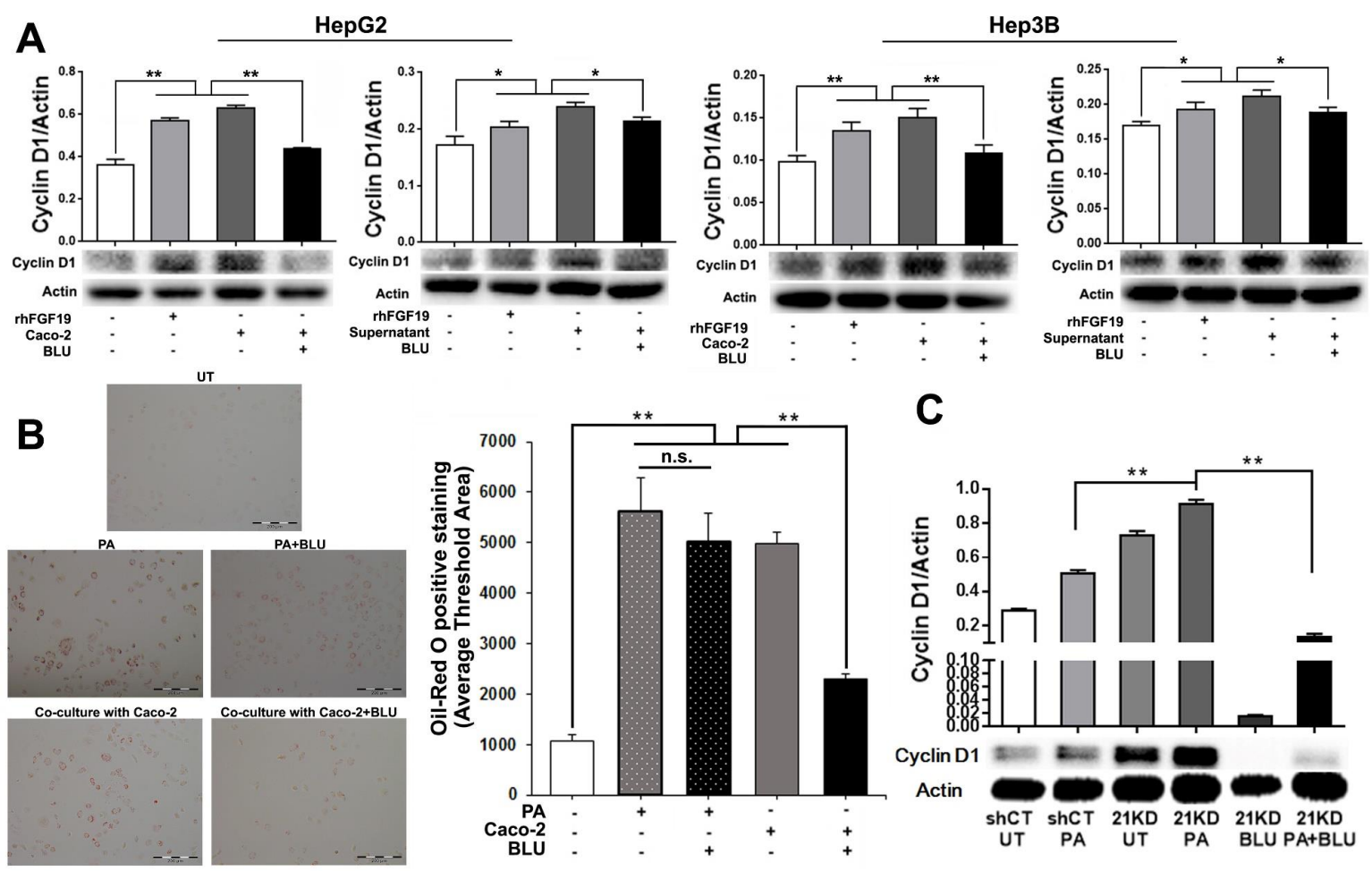

C

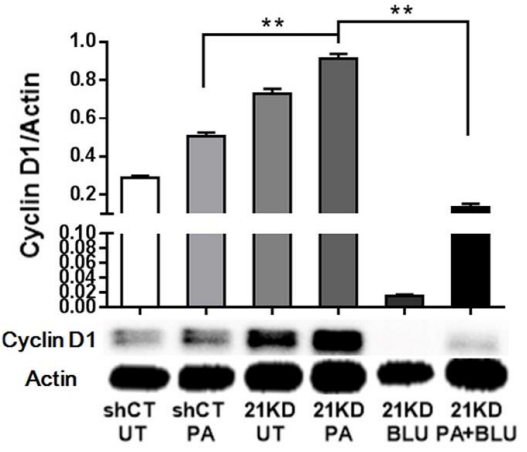

Figure 6. A: Western blot analysis for cyclin D1 protein levels in HepG2 cells and Hep3B cells co-cultured with Caco-2 cells, with rhFGF19 treatment at 100 ng/ml for 24 hours, with co-culture supernatant treatment for 24 hours, and with BLU9931 treatment at 100nM for 24 hours. B: Lipid accumulation detected by Oil Red O staining along with computer-imaging analysis in Hep3B cells challenged with PA (palmic acid) at 100uM for 48 hours, and treated with BLU9931 treatment at $100 \mathrm{nM}$ for 24 hours. C: Western blot analysis for the protein levels of cyclin D1 in shCT-FL83B cells and FGF21KD-FL83B cells challenged with PA at 100uM for 24 hours, and treated with BLU9931 at 100nM for 24 hours. UT: untreated; PA: palmic acid; shCT: shCT-FL83B cells; 21KD: FGF21KD-FL83B cells. n.s., no significance; *, $\mathrm{p}<0.05$; **, $\mathrm{p}<0.01$.
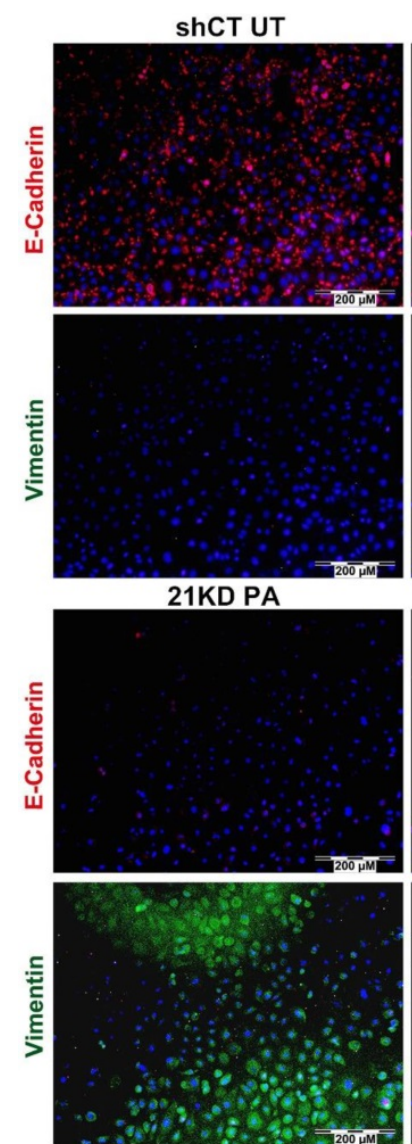

$21 \mathrm{KD}$ UT

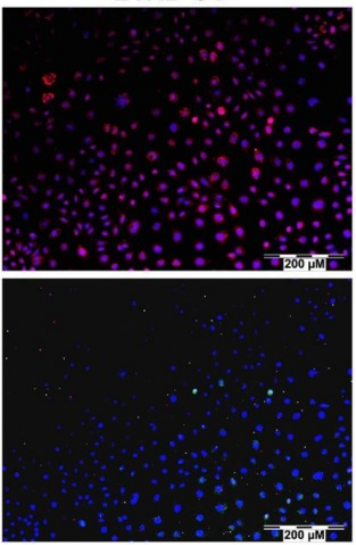

21KD BLU
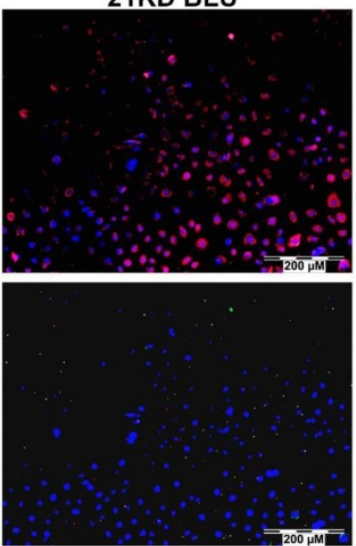

ShCT PA

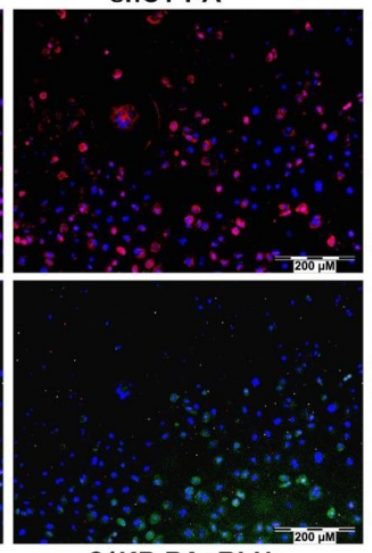

21KD PA+BLU
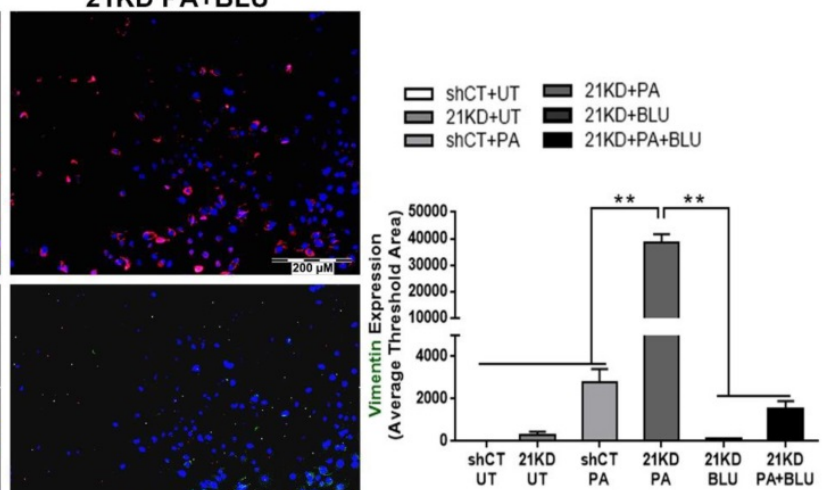

Figure 7. E-cadherin/Vimentin expressions by immunofluorescent staining in shCT-FL83B cells and FGF21KD-FL83B cells challenged with PA at $100 \mathrm{uM}$ for 24 hours, and treated with BLU9931 at 100nM for 24 hours. UT: untreated; PA: palmic acid; shCT: shCT-FL83B cells; 21KD: FGF21KD-FL83B cells. *, p<0.05; **, p<0.01. 
The liver generally maintains an appropriate size in adults. Loss of hepatocytes because of repetitive injury allows the liver to begin growing which is accepted as a fundamental mechanism(s) in cancer biology. Emerging studies have shown that FGFR4 play important roles in liver regeneration and carcinogenesis. For post-hepatectomy liver regeneration, FGFR4 was found to complex with $\beta$-klotho on hepatocyte membrane, upon FGF19/FGF15 binding, to initiate regeneration and orchestrate BAs acid detoxification as a protective mechanism in concurrence with the proliferative signaling [49]. In HCC, FGF19 elicits cell proliferation [50] and promotes the HCC cell survival and increased resistance to apoptosis via activating a FGFR4-GSK3 $\beta$-Nrf2 signaling cascade [51]. The aberrant FGFR4 signaling has been reported to be an oncogenic-driver pathway for HCC development [52]. In our studies, up-regulated FGF15 and FGFR4/ $\beta$-klotho were found to coupled fibrosis and deleterious cellular events during the NASH development in FGF21KO mice. These findings are in accordance with our previous studies in HFD- or diabetes- induced NASH mice [6,8]. This study is mainly designed to investigate FGF15/FGFR4 expression during the NASH development in FGF21KO mice. The major limitation of this study is lack of FGF15KO/overexpressing mice to elucidate the molecular mechanisms of FGF15/FGFR4 signaling pathway contributing to NASH progression and HCC development. Further studies are needed to determine the roles of FGF15/FGFR4/ $\beta$-klotho as well as the downstream signaling during NASH progression. The FGFR4/ $\beta$-klotho/BAs associated carcinogenesis via Gut-Liver axis is also an important issues and needs to further study in NASH-HCC transition models.

\section{Conclusion}

The increased FGF15 production in NASHFGF21KO mice could not substitute for FGF21 to compensate its lipid metabolic benefits thereby to prevent NASH development. The up-regulated FGFR4 signaling was coupled to cellular and molecular events which might associate to carcinogenic transformation. This study provided a new insight into FGF15 and FGFR4 signaling during $\mathrm{NASH}$ development and the potential pharmacological application to target FGFR4 for treatment in advanced NASH.

\section{Abbreviations}

FGF21: Fibroblast growth factor21; FGF15/19: Fibroblast growth factor15/19; NASH: Nonalcoholic steatohepatitis; HFMCD: High fat methionine-choline deficient; FFA: free fatty acid; FA: fatty acid; KO: knockout; NAFLD: Non-alcoholic fatty liver disease; HCC: Hepatocellular carcinoma; ALT: Alanine aminotransferase; TG: Triglyceride; H\&E: Hematoxylin and eosin; NAS: NAFLD activity score; shCT: shRNA Control; PA: Palmic acid.

\section{Supplementary Material}

Supplementary figures and tables. http://www.ijbs.com/v17p2576s1.pdf

\section{Acknowledgements}

\section{Funding}

Research reported in this publication was supported partly by an Institutional Development Award (IDeA) from the NIGMS of the National Institutes of Health under grant number P20GM113226. The content is solely the responsibility of the authors and does not necessarily represent the official views of the National Institutes of Health.

\section{Author Contributions}

Youxi Yu worked for the animal models, IHC and western blot, data analysis and manuscript draft writing. Xiaoju shi, Qianqian Zheng, Min Tan and Xingtong Wang worked for RT-PCR and serum biomarkers measurements. Xingkai Liu, Guoyue Lv, and Ping Zhang contributed to clinical consultant and experimental design and experimental design. Robert C. Martin contributed to the experimental design, clinical consultant and manuscript English checking. Yan Li contributed to data analysis and manuscript writing and editing.

\section{Ethics approval and consent to participate}

The animal procedures were approved by the Institutional Animal Care and Use Committee of University of Louisville, which is certified by the American Association for Accreditation of Laboratory Animal Care.

\section{Competing Interests}

The authors have declared that no competing interest exists.

\section{References}

1. Marengo A, Rosso C, Bugianesi E. Liver Cancer: Connections with Obesity, Fatty Liver, and Cirrhosis. Annu Rev Med. 2016; 67: 103-17.

2. McPherson S, Hardy T, Henderson E, Burt AD, Day CP, Anstee QM. Evidence of NAFLD progression from steatosis to fibrosing-steatohepatitis using paired biopsies: implications for prognosis and clinical management. J Hepatol. 2015; 62: 1148-55.

3. Leung C, Yeoh SW, Patrick D, Ket S, Marion K, Gow P, et al. Characteristics of hepatocellular carcinoma in cirrhotic and non-cirrhotic non-alcoholic fatty liver disease. World J Gastroenterol. 2015; 21: 1189-96.

4. Guzman G, Brunt EM, Petrovic LM, Chejfec G, Layden TJ, Cotler SJ. Does nonalcoholic fatty liver disease predispose patients to 
hepatocellular carcinoma in the absence of cirrhosis? Arch Pathol Lab Med. 2008; 132: 1761-6.

5. Tilg H, Moschen A. Update on nonalcoholic fatty liver disease: genes involved in nonalcoholic fatty liver disease and associated inflammation. Curr Opin Clin Nutr Metab Care. 2010; 13: 391-6.

6. Cui G, Martin RC, Jin H, Liu X, Pandit H, Zhao H, et al. Up-regulation of FGF15/19 signaling promotes hepatocellular carcinoma in the background of fatty liver. Journal of experimental \& clinical cancer research : CR. 2018; 37: 136.

7. Cui G, Martin RC, Liu X, Zheng Q, Pandit H, Zhang P, et al. Serological biomarkers associate ultrasound characteristics of steatohepatitis in mice with liver cancer. Nutrition \& metabolism. 2018; 15: 71.

8. Liu X, Zhang P, Martin RC, Cui G, Wang G, Tan Y, et al. Lack of fibroblast growth factor 21 accelerates metabolic liver injury characterized by steatohepatities in mice. Am J Cancer Res. 2016; 6: 1011-25.

9. Zhang Q, Li Y, Liang T, Lu X, Liu X, Zhang C, et al. Loss of FGF21 in diabetic mouse during hepatocellular carcinogenetic transformation. Am J Cancer Res. 2015; 5: 1762-74.

10. Beenken A, Mohammadi M. The FGF family: biology, pathophysiology and therapy. Nat Rev Drug Discov. 2009; 8: 235-53.

11. Owen BM, Mangelsdorf DJ, Kliewer SA. Tissue-specific actions of the metabolic hormones FGF15/19 and FGF21. Trends Endocrinol Metab. 2015; $26: 22-9$.

12. Fisher FM, Maratos-Flier E. Understanding the Physiology of FGF21. Annual review of physiology. 2016; 78: 223-41.

13. Inagaki T, Dutchak P, Zhao G, Ding X, Gautron L, Parameswara V, et al. Endocrine regulation of the fasting response by PPARalpha-mediated induction of fibroblast growth factor 21. Cell Metab. 2007; 5: 415-25.

14. Adams AC, Yang C, Coskun T, Cheng CC, Gimeno RE, Luo Y, et al. The breadth of FGF21's metabolic actions are governed by FGFR1 in adipose tissue. MolMetab. 2012; 2: 31-7.

15. Ye M, Lu W, Wang X, Wang C, Abbruzzese JL, Liang G, et al. FGF21-FGFR1 Coordinates Phospholipid Homeostasis, Lipid Droplet Function, and ER Stress in Obesity. Endocrinology. 2016; 157: 4754-69.

16. Guan D, Zhao L, Chen D, Yu B, Yu J. Regulation of fibroblast growth factor 15/19 and 21 on metabolism: in the fed or fasted state. J Transl Med. 2016; 14: 63.

17. Gaich G, Chien J, Fu HD, Kharitonenkov A, Moller D. Effects of an FGF21 Analog in Patients With Type 2 Diabetes. Diabetes. 2013; 62: A28-A.

18. Gaich G, Chien JY, Fu H, Glass LC, Deeg MA, Holland WL, et al. The effects of LY2405319, an FGF21 analog, in obese human subjects with type 2 diabetes. Cell Metab. 2013; 18: 333-40.

19. Lee JH, Kang YE, Chang JY, Park KC, Kim HW, Kim JT, et al. An engineered FGF21 variant, LY2405319, can prevent non-alcoholic steatohepatitis by enhancing hepatic mitochondrial function. Am J Transl Res. 2016; 8: 4750-63.

20. Alvarez-Sola G, Uriarte I, Latasa MU, Fernandez-Barrena MG, Urtasun R, Elizalde M, et al. Fibroblast growth factor 15/19 (FGF15/19) protects from diet-induced hepatic steatosis: development of an FGF19-based chimeric molecule to promote fatty liver regeneration. Gut. 2017; 66: 1818-28.

21. Harrison SA, Rinella ME, Abdelmalek MF, Trotter JF, Paredes $\mathrm{AH}$, Arnold HL, et al. NGM282 for treatment of non-alcoholic steatohepatitis: a multicentre, randomised, double-blind, placebo-controlled, phase 2 trial. Lancet. 2018; 391: 1174-85.

22. Valenti L, Nobili V. NGM282: a step forward in the nonalcoholic steatohepatitis treatment landscape? Hepatobiliary Surg Nutr. 2018; 7: 484-6.

23. Lin BC, Desnoyers LR. FGF19 and cancer. Adv Exp Med Biol. 2012; 728: 183-94.

24. Huang X, Yang C, Luo Y, Jin C, Wang F, McKeehan WL. FGFR4 prevents hyperlipidemia and insulin resistance but underlies high-fat diet induced fatty liver. Diabetes. 2007; 56: 2501-10.

25. Stephenson K, Kennedy L, Hargrove L, Demieville J, Thomson J, Alpini G, et al. Updates on Dietary Models of Nonalcoholic Fatty Liver Disease: Current Studies and Insights. Gene Expr. 2018; 18: 5-17.

26. Brunt EM, Kleiner DE, Wilson LA, Belt P, Neuschwander-Tetri BA, Network NCR. Nonalcoholic fatty liver disease (NAFLD) activity score and the histopathologic diagnosis in NAFLD: distinct clinicopathologic meanings. Hepatology. 2011; 53: 810-20.

27. Li S, Hsu DD, Li B, Luo X, Alderson N, Qiao L, et al. Cytoplasmic tyrosine phosphatase Shp2 coordinates hepatic regulation of bile acid and FGF15/19 signaling to repress bile acid synthesis. Cell Metab. 2014; 20: 320-32.

28. Al-Aqil FA, Monte MJ, Peleteiro-Vigil A, Briz O, Rosales R, Gonzalez R, et al. Interaction of glucocorticoids with FXR/FGF19/FGF21-mediated ileum-liver crosstalk. Biochim Biophys Acta Mol Basis Dis. 2018; 1864: 2927-37.

29. Hagel M, Miduturu C, Sheets M, Rubin N, Weng W, Stransky N, et al. First Selective Small Molecule Inhibitor of FGFR4 for the Treatment of Hepatocellular Carcinomas with an Activated FGFR4 Signaling Pathway. Cancer Discov. 2015; 5: 424-37.

30. Xie MH, Holcomb I, Deuel B, Dowd P, Huang A, Vagts A, et al. FGF-19, a novel fibroblast growth factor with unique specificity for FGFR4. Cytokine. 1999; 11: 729-35.

31. Fon Tacer K, Bookout AL, Ding X, Kurosu H, John GB, Wang L, et al. Research resource: Comprehensive expression atlas of the fibroblast growth factor system in adult mouse. Mol Endocrinol. 2010; 24: 2050-64.

32. Inagaki T, Choi M, Moschetta A, Peng L, Cummins CL, McDonald JG, et al. Fibroblast growth factor 15 functions as an enterohepatic signal to regulate bile acid homeostasis. Cell Metab. 2005; 2: 217-25.

33. Naugler WE, Tarlow BD, Fedorov LM, Taylor M, Pelz C, Li B, et al. Fibroblast Growth Factor Signaling Controls Liver Size in Mice With Humanized Livers. Gastroenterology. 2015; 149: 728-40 e15.

34. You M, Zhou Z, Daniels M, Jogasuria A. Endocrine Adiponectin-FGF15/19 Axis in Ethanol-Induced Inflammation and Alcoholic Liver Injury. Gene Expr. 2018; 18: 103-13.

35. Ge H, Zhang J, Gong Y, Gupte J, Ye J, Weiszmann J, et al. Fibroblast growth factor receptor 4 (FGFR4) deficiency improves insulin resistance and glucose metabolism under diet-induced obesity conditions. J Biol Chem. 2014; 289: 30470-80.

36. Lutz SZ, Hennige AM, Peter A, Kovarova M, Totsikas C, Machann J, et al. The Gly385(388)Arg Polymorphism of the FGFR4 Receptor Regulates Hepatic Lipogenesis Under Healthy Diet. J Clin Endocrinol Metab. 2019; 104: 2041-53.

37. Liu Y, Cao M, Cai Y, Li X, Zhao C, Cui R. Dissecting the Role of the FGF19-FGFR4 Signaling Pathway in Cancer Development and Progression. Front Cell Dev Biol. 2020; 8: 95.

38. Cariello M, Moschetta A. Fibroblast growth factor 21: a new liver safeguard. Hepatology. 2014; 60: 792-4

39. Byun S, Seok S, Kim YC, Zhang Y, Yau P, Iwamori N, et al. Fasting-induced FGF21 signaling activates hepatic autophagy and lipid degradation via JMJD3 histone demethylase. Nat Commun. 2020; 11: 807.

40. Fisher FM, Chui PC, Antonellis PJ, Bina HA, Kharitonenkov A, Flier JS, et al. Obesity is a fibroblast growth factor 21 (FGF21)-resistant state. Diabetes. 2010; 59: 2781-9.

41. Tomlinson E, Fu L, John L, Hultgren B, Huang X, Renz M, et al. Transgenic mice expressing human fibroblast growth factor-19 display increased metabolic rate and decreased adiposity. Endocrinology. 2002; 143: $1741-7$

42. Zhou M, Learned RM, Rossi SJ, DePaoli AM, Tian H, Ling L. Engineered FGF19 eliminates bile acid toxicity and lipotoxicity leading to resolution of steatohepatitis and fibrosis in mice. Hepatol Commun. 2017; 1: 1024-42.

43. Schumacher JD, Kong B, Pan Y, Zhan L, Sun R, Aa J, et al. The effect of fibroblast growth factor 15 deficiency on the development of high fat diet induced non-alcoholic steatohepatitis. Toxicol Appl Pharmacol. 2017; 330: 1-8.

44. Nishimura T, Utsunomiya $\mathrm{Y}$, Hoshikawa M, Ohuchi $\mathrm{H}$, Itoh N. Structure and expression of a novel human FGF, FGF-19, expressed in the fetal brain. Biochim Biophys Acta. 1999; 1444: 148-51.

45. Ellis EC, Naugler WE, Parini P, Mork LM, Jorns C, Zemack H, et al. Mice with chimeric livers are an improved model for human lipoprotein metabolism. PLoS One. 2013; 8: e78550.

46. Meadows V, Kennedy L, Kundu D, Alpini G, Francis H. Bile Acid Receptor Therapeutics Effects on Chronic Liver Diseases. Front Med (Lausanne). 2020; 7: 15.

47. Alvarez-Sola G, Uriarte I, Latasa MU, Jimenez M, Barcena-Varela M, Santamaria E, et al. Bile acids, FGF15/19 and liver regeneration: From mechanisms to clinical applications. Biochim Biophys Acta Mol Basis Dis. 2018; 1864: 1326-34.

48. Fu T, Kim YC, Byun S, Kim DH, Seok S, Suino-Powell K, et al. FXR Primes the Liver for Intestinal FGF15 Signaling by Transient Induction of beta-Klotho. Mol Endocrinol. 2016; 30: 92-103.

49. de Haan L, van der Lely SJ, Warps AK, Hofsink Q, Olthof PB, de Keijzer MJ, et al. Post-hepatectomy liver regeneration in the context of bile acid homeostasis and the gut-liver signaling axis. J Clin Transl Res. 2018; 4: $1-46$.

50. Latasa MU, Salis F, Urtasun R, Garcia-Irigoyen O, Elizalde M, Uriarte I, et al. Regulation of amphiregulin gene expression by beta-catenin signaling in human hepatocellular carcinoma cells: a novel crosstalk between FGF19 and the EGFR system. PLoS One. 2012; 7: e52711.

51. Teng Y, Zhao H, Gao L, Zhang W, Shull AY, Shay C. FGF19 Protects Hepatocellular Carcinoma Cells against Endoplasmic Reticulum Stress 
via Activation of FGFR4-GSK3beta-Nrf2 Signaling. Cancer Res. 2017; 77: 6215-25.

52. Raja A, Park I, Haq F, Ahn SM. FGF19-FGFR4 Signaling in Hepatocellular Carcinoma. Cells. 2019; 8. 